\title{
Using bispectral (IR-Visible) Unmanned Aerial Vehicle (UAV) for detailed aerospace structures inspections
}

\author{
by L. Gavérina*, C. Trottier*, F. Passilly and J.-M. Roche*
}

* ONERA, Materials and Structures Department, Châtillon, 92320, France, ludovic.gaverina@onera.fr

\section{Abstract}

In this paper, a Non Destructive Testing approach by active infrared thermography mounted on the Unmanned Aerial Vehicle (UAV) is used to investigate damage due to lightning-strike in composite specimen. In this study, an experimental bench is developed using pulsed thermography in reflection mode and compare to static flash method in order to detect delamination of this material.

\section{Introduction}

The increase in aircraft availability, the major industrial challenge, the reduction of duration and / or number of maintenance operations. Currently, the control of the state of health of aircraft ending periodically, systematically, which may lead to unnecessary immobilization ground devices in the event that they ultimately prove to be undamaged. The impact of the costs generated by these inspections is reduced to nothing: the controls are then not done periodically but only when they are needed. In order to allow this individualization, it is necessary that automated the non-destructive testing procedures by using Unmanned Aerial Vehicle. Recently, the French company Parrot $\AA$ has developed an bispectral (IR-Visible) UAV Anafi Thermal. In this work, we propose to realize a simple flash method combined with UAV active IR thermography systems on large surfaces and compare these results to the static flash methods

\section{Classical flash thermography}

In the case of in reflection mode, the heating pulse is applied on the same side of the specimen which is observed by the infrared camera.

In the case of in reflection mode, the temperature increase of a sample after instantaneous heating by adiabatic conditions using an one-dimensional model [1], the normalized temperature increase is written as follow:

$$
T_{N}=\frac{T(z=e, t)}{T_{\lim }}=1+2 \sum_{n=1}^{\infty} \exp \left(\frac{-n^{2} \pi^{2}}{e^{2}} a t\right)
$$

$$
\text { With } T_{\text {lim }}=\frac{Q a}{\lambda e}
$$

For the investigation, two halogen lamps whit $6 \mathrm{~kJ}$ each are used to provide the thermal solicitation to the sample. The surface of the specimen is preliminary painted to have an emissivity close to 0.97 . The IR camera which was used during experiments is a FLIR X6540sc MWIR camera $(640 \times 512$ pixels, NETD 20mK, pitch $15 \mu \mathrm{m}$, spectral band $1.5-5 \mu \mathrm{m}$ ). The frame rate of the camera was $10 \mathrm{~Hz}$. Experiments in reflection mode were carried out on CFRP specimens wich the damage induced by lightning strike [2].

Figure.1.a shows the normalized thermogram of front face of CFRP specimen submitted to a flash heating. Regarding the thermograms in reflection mode, they are obtained by dividing the temperatures by the final asymptotic value. The presence of the defects due to the lightning strike is clearly seen. 
a)

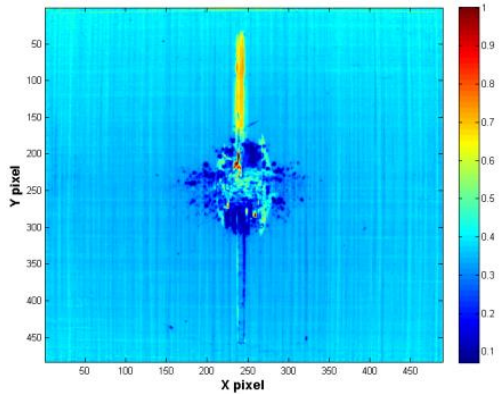

Fig. 1. Front-face thermograms at optimal time: (a)

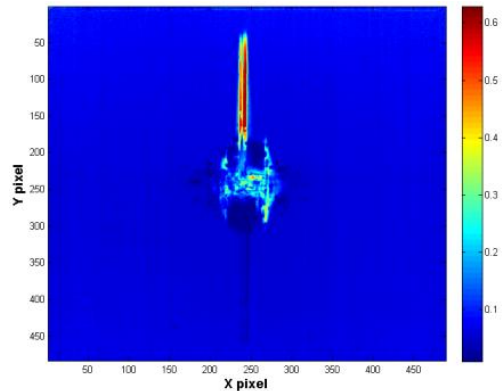

(a) $0.19 \mathrm{~s}$ and (d) late time (1.9s)

\section{First investigation with an UAV}

For the investigation, the IR camera mounted to UAV (Anafi Thermal) is a FLIR Lepton 3.5 camera $(160 \times 120$ pixels, NETD $50 \mathrm{mK}$, pitch $12 \mu \mathrm{m}$, spectral band $8-14 \mu \mathrm{m}$ ). The maximum frame rate of the camera was $9 \mathrm{~Hz}$.

a)

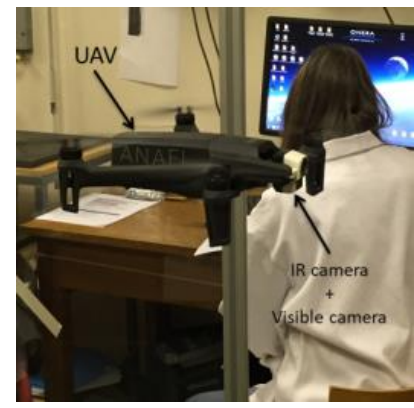

b)

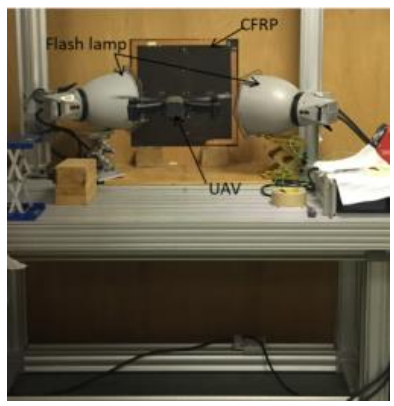

Fig. 2. (a) Photography of the Anafi Thermal and (b) photography of the thermography set-up.

Figure. 3 shows the images merged from the visible domain (RGB) and the thermal infrared domain of front face of CFRP specimen submitted to a flash heating. The new thermal sequence obtained is similar to the ones typically observed in a static flash (Figure 1).

a)

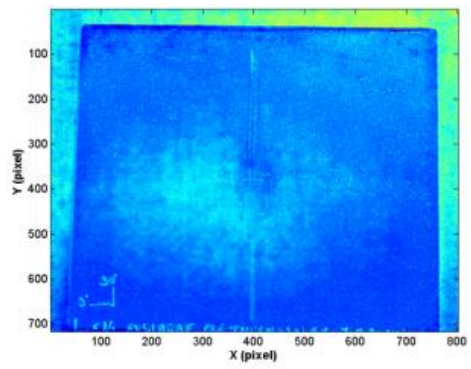

Fig. 3. Front-face thermograms at optimal time: (a) before flash excitation and (b) $0.19 \mathrm{~s}$

\section{REFERENCES}

[1] Parker W.J., Jenkins R.J., Butler C.P., Abbott G.L., "Flash method of determining thermal diffusivity, heat capacity and thermal conductivity", J. Applied Physics, Vol. 32, pp. 1679-1684, Sept. 1961.

[2] Roche, J. M., Passilly, F., Beauchêne, P., Zaepffel, C., Martins, R. S., Balageas, D. (2018, June). "IR thermography for lightning-strike damage monitoring in composite materials". In QIRT Berlin 2018. 